\title{
Impact of rainfall spatial aggregation on the identification of debris flow occurrence thresholds
}

\author{
Francesco Marra $^{1}$, Elisa Destro ${ }^{2}$, Efthymios I. Nikolopoulos ${ }^{3}$, Davide Zoccatelli ${ }^{1,2}$, Jean Dominique Creutin ${ }^{4}$, \\ Fausto Guzzetti ${ }^{5}$, and Marco Borga ${ }^{2}$ \\ ${ }^{1}$ Institute of Earth Sciences, Hebrew University of Jerusalem, 91904, Jerusalem, Israel \\ ${ }^{2}$ Department of Land, Environment, Agriculture and Forestry, University of Padova, Padua, Italy \\ ${ }^{3}$ Department of Civil and Environmental Engineering, University of Connecticut, Storrs, CT, USA \\ ${ }^{4}$ Institut des Géosciences pour l'Environnement, Université de Grenoble Alpes/CNRS, Grenoble, France \\ ${ }^{5}$ Istituto di Ricerca per la Protezione Idrogeologica, Consiglio Nazionale delle Ricerche, Perugia, Italy
}

Correspondence to: Francesco Marra (marra.francesco@mail.huji.ac.il)

Received: 24 May 2017 - Discussion started: 19 June 2017

Revised: 15 August 2017 - Accepted: 16 August 2017 - Published: 12 September 2017

\begin{abstract}
The systematic underestimation observed in debris flow early warning thresholds has been associated with the use of sparse rain gauge networks to represent highly non-stationary rainfall fields. Remote sensing products permit concurrent estimates of debris-flow-triggering rainfall for areas poorly covered by rain gauges, but the impact of using coarse spatial resolutions to represent such rainfall fields is still to be assessed. This study uses fine-resolution radar data for $\sim 100$ debris flows in the eastern Italian Alps to (i) quantify the effect of spatial aggregation (1-20 km grid size) on the estimation of debris-flow-triggering rainfall and on the identification of early warning thresholds and (ii) compare thresholds derived from aggregated estimates and rain gauge networks of different densities. The impact of spatial aggregation is influenced by the spatial organization of rainfall and by its dependence on the severity of the triggering rainfall. Thresholds from aggregated estimates show $8-21 \%$ variation in the parameters whereas $10-25 \%$ systematic variation results from the use of rain gauge networks, even for densities as high as $1 / 10 \mathrm{~km}^{-2}$.
\end{abstract}

\section{Introduction}

Debris flows are among the most impactful natural hazards in mountainous areas (Dowling and Santi, 2014; Badoux et al., 2016). They are primarily triggered by heavy rainfall hitting headwater catchments and, in many areas, their frequency is expected to increase in response to the intensification of the hydrological cycle caused by global warming (Westra et al., 2014; Gariano and Guzzetti, 2016; Dietrich and Krautblatter, 2017). Forecasting their occurrence is fundamental to save lives and property and relies on early warning systems (Borga et al., 2014).

Operational debris flow early warning systems are largely based on empirical thresholds: meteorological and/or hydrological conditions above which debris flows are likely to occur (Caine, 1980). These thresholds are often defined as relationships between rain depth (or intensity) and duration, and are identified from past records (Guzzetti et al., 2008). Although rain-gauge-based thresholds are used in different regions worldwide (Jakob et al., 2012; Segoni et al., 2015; Ma et al., 2015; Piciullo et al., 2017), their accuracy depends on the abundance and quality of in situ rainfall measurements and debris flow observations (Nikolopoulos et al., 2014).

The uncertainty related to rain-gauge-based estimates of debris-flow-triggering rainfall is emphasized by the specific spatial organization of the triggering rainfall events. Recent studies, based on fine-resolution radar estimates in the eastern Italian Alps, showed that the uncertainty related to raingauge-based estimates of debris-flow-triggering rainfall is emphasized by the specific spatial organization of the triggering rainfall events: local rain depth peaks are often associated with the debris flow initiation points (Marra et al., 2016), and the occurrence and magnitude of such peaks depend on the severity of the triggering rainfall (Destro et al., 
2017). This non-stationarity of the triggering rainfall fields causes systematic underestimation in the rain gauge estimates which propagates to the identification of the threshold relationships, decreasing their efficiency in separating triggering versus non-triggering events (Nikolopoulos et al., 2014, 2015a; Marra et al., 2014; Abancó et al., 2016).

Remote-sensing rainfall products provide debris-flowconcurrent estimates at the regional and global scales, allowing for the monitoring of areas poorly covered by rain gauge networks. Derivation of debris flow occurrence thresholds from such data sets can be used to develop local, regional, or global warning systems. Moreover, it enables a direct and consistent comparison between thresholds in different regions, allowing us to separate the contribution of hydrogeomorphological features other than rainfall, such as geology, pedology, and slope, to the debris flow triggering. However, the use of remote-sensing rainfall estimates is hampered by two factors in particular: the coarse resolution of the products and the uncertainty due to current limitations in the retrieval algorithms. The vast majority of the studies dealing with remote-sensing precipitation error over complex terrain have been focused on hydrological applications rather than debris flow or landslide triggering (Mei et al., 2014; Derin et al., 2016; Maggioni et al., 2017), or evaluated the combined effect of resolution and estimation uncertainty without separating the contribution of each factor (Hong et al., 2006; Kirschbaum et al., 2012, 2013; Rossi et al., 2017; Nikolopoulos et al., 2017). Particularly in the case of debris flows, the small size of the initiation catchments is expected to highlight the impact of spatial resolution. It is thus important to quantify the effect of this factor on threshold-based early warning systems.

In this study, we analyse the effect of using coarseresolution data for the identification of debris flow occurrence thresholds, leaving aside considerations on their prediction efficiency. In particular, (i) we quantify the impact of rainfall spatial aggregation, representing the resolution of remotely sensed estimates, on the estimation error of debrisflow-triggering rainfall, and on the identification of the parameters of debris flow occurrence thresholds, and (ii) we compare thresholds derived from spatially aggregated rainfall estimates with those obtained from synthetic rain gauge networks of different densities, in order to assess the relative advantages of the two rainfall estimation methods. We explore the usual spatial scales of radar and satellite products (1-20 km grid size) and rain gauge network densities of $1 / 10-1 / 100 \mathrm{~km}^{-2}$.

\section{Impact of spatial aggregation on the estimation of debris-flow-triggering rainfall}

We build upon a unique high-resolution ( $1 \mathrm{~km}$ grid size, $5 \mathrm{~min}$ ) data archive of radar rainfall estimates available for 11 storms which collectively triggered 99 debris flows in the eastern Italian Alps (Fig. 1). All the events are represented by channelized debris flows triggered in very small basins. Event duration ranged between 1.5 and $26 \mathrm{~h}$ and the triggering rainfall between 8 and $180 \mathrm{~mm}$. This data set is a representative sample $(\sim 20 \%)$ of the debris flows that occurred in the study region in the period 2000-2014 (Nikolopoulos et al., 2015b). See Destro et al. (2017) for additional information on the debris flow database and on the storm events. Weather radar rainfall estimates were corrected for errors due to attenuation in heavy rain, wet radome attenuation, beam blockage, and vertical profile of reflectivity (Marra et al., 2014), and were then gauge-adjusted at the event scale using quality-controlled rain gauge measurements. The radar data quality was checked at each step of the elaboration (Marra et al., 2014), and, as a result, the radar estimates are considered the best available spatial representation of debris-flowtriggering rainfall. To the authors' knowledge, this is among the largest and most accurate radar-based dataset of debrisflow-triggering rainfall currently available worldwide.

Rainfall events were identified as separated by $24 \mathrm{~h}$ dry periods (Nikolopoulos et al., 2014). The triggering rain depth $(E)$ was computed as the total rainfall estimated above the triggering location during the event duration $(D)$. Since no information is available on the exact time of occurrence of the debris flows, the events were extended until the end of the rainfall. Spatially aggregated estimates were computed by spatially averaging the radar estimates on $1-20 \mathrm{~km}$ grid size. These scales reproduce the equivalent areal resolution of the most commonly used remote-sensing rainfall products (Hsu et al., 1997; Hong et al., 2004; Huffman et al., 2007; Joyce et al., 2004; Huffman et al., 2015). To quantify the estimation error due to spatial aggregation, we used the relative error (RE), calculated as

$\mathrm{RE}=\frac{E}{E^{*}}$,

where $E$ is the aggregated rainfall estimate and $E^{*}$ is the corresponding $1 \mathrm{~km}$ grid size value. Median and interquartile range (IQR) of the RE were used to characterize the error distribution.

Following the results reported by Destro et al. (2017), we related the distribution of the estimation error to the severity of the triggering rainfall. The return period of the triggering rainfall $(T)$ was computed from depth-durationfrequency curves derived for the region using the method of the $L$-moments, and a kriging interpolation procedure in a regional generalized extreme values framework (Destro et al., 2017). The severity of the debris-flow-triggering rainfall was classified as mild ( $T \leq 2$ years, 21 debris flows), moderate $(2<T \leq 50$ years, 41 debris flows), and severe $(T>50$ years, 37 debris flows), depending on the return period of the $1 \mathrm{~km}$ grid size rainfall estimated above the triggering locations. Figure 2 shows the relative error for rainfall estimates aggregated on $1-20 \mathrm{~km}$ grid sizes. Results are shown for all 


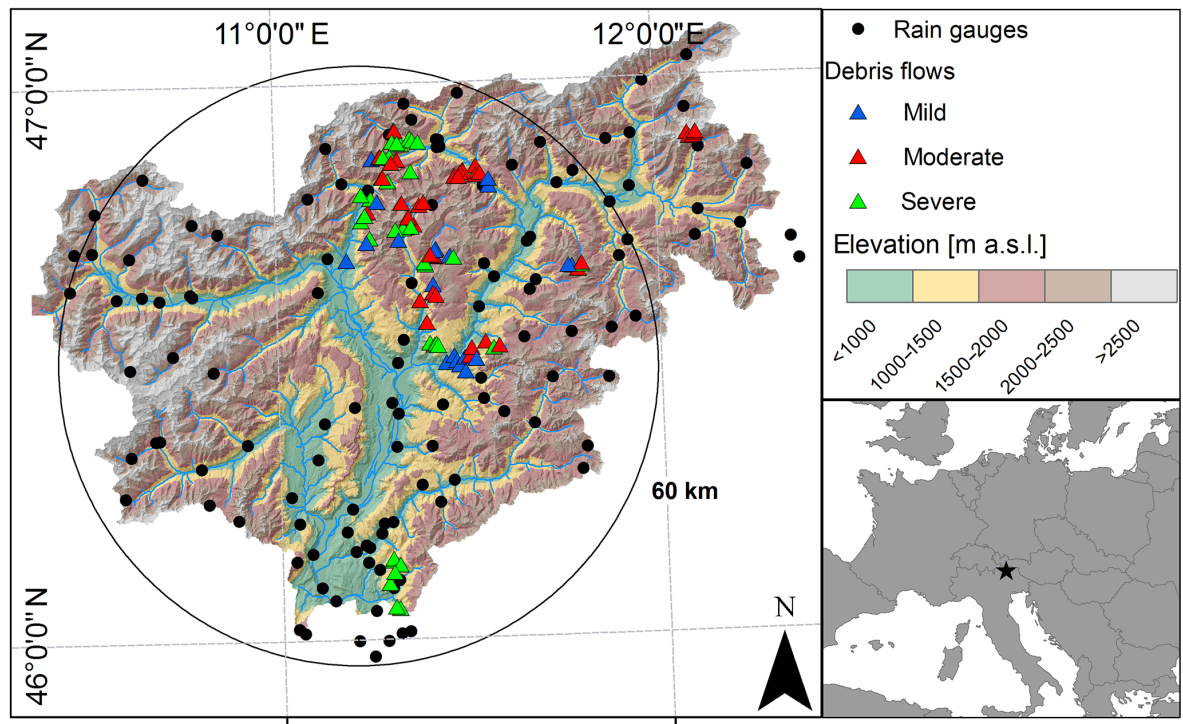

Figure 1. Map of the study area including terrain elevation, rain gauge network (dots), and debris flows included in the study (triangles). Location of the study area within Europe is shown.

the debris flow events (Fig. 2a) and for the three severity classes separately (Fig. 2b).

When all the events are considered, the spatial aggregation yields a consistent decrease in the estimated rainfall, with RE reaching 0.52 for $20 \mathrm{~km}$ grid size while the IQR increases up to $\sim 0.4$ for aggregation scales of $\sim 13 \mathrm{~km}$ grid size. This suggests that an approximate $50 \%$ underestimation of the triggering rainfall amount is expected at $20 \mathrm{~km}$ grid size as a result of the spatial aggregation alone. This pattern is caused by local rain depth peaks that correspond to the area most severely hit by the event-generating convective cells. Such peaks are frequently observed in close proximity of the triggering locations (Marra et al., 2016) so that, when rainfall is spatially aggregated, lower rainfall amounts are progressively included in the estimate.

Figure $2 b$ shows that the scale dependency pattern depends strongly on the severity of the triggering rainfall. Moderate and severe events (i.e. the 78 events triggered by $T>2$ year rainfall) exhibit similar underestimation, dominating the distribution observed in the general case. Conversely, mild events ( $T \leq 2$ years) show a substantially different pattern, with aggregated estimates overestimated even for $20 \mathrm{~km}$ grid sizes. In fact, as shown by Destro et al. (2017), debris flows triggered by short-return-period rainfall are often located close, but not corresponding, to the local rain depth peaks, so that the spatial aggregation is expected to include larger rain depths. The IQR is as high as 0.93 for $12 \mathrm{~km}$ grid size, and decreases to 0.8 for $20 \mathrm{~km}$ grid size.

\section{Impact of spatial aggregation on the identification of debris flow occurrence thresholds}

Rainfall thresholds for the occurrence of debris flows were derived in the form of power law relationships between the triggering rain depth $(E)$ and the rainfall duration $(D)$, as in (Guzzetti et al., 2008)

$E=\alpha_{p} \cdot D^{\beta}$.

The use of rainfall depth is equivalent to the use of rain intensity, but avoids the need to calculate rain intensity from the event rain depth and duration. The parameters of the threshold were objectively identified from the empirical data using the frequentist method proposed by Brunetti et al. (2010). In an operational environment, the spatial-temporal characteristics of rainfall have rarely been considered, despite the observed non-stationarity of the rainfall fields around the debris-flow-triggering locations reported by Marra et al. (2016). Because our objective is to analyse the impact of this non-stationarity on the use of spatially aggregated rainfall information, it is crucial for us to focus on the triggering events, i.e. on the events in which the systematic spatial feature is observed, and to use an objective and straightforward method, such as the frequentist, that allows a clear interpretation of the results. The shape parameter $\beta$ was derived from the linear regression of the $(E, D)$ pairs plotted on logarithmic scale; the scale parameter $\alpha_{p}$ was calculated assuming a normal distribution of the regression residuals (log residuals, hereinafter), and setting the required exceedance probability $p$ to the desired level. Therefore, the offset of the rainfall threshold with respect to the regression line depends on the distribution (i.e. standard deviation) of the log residuals. In 

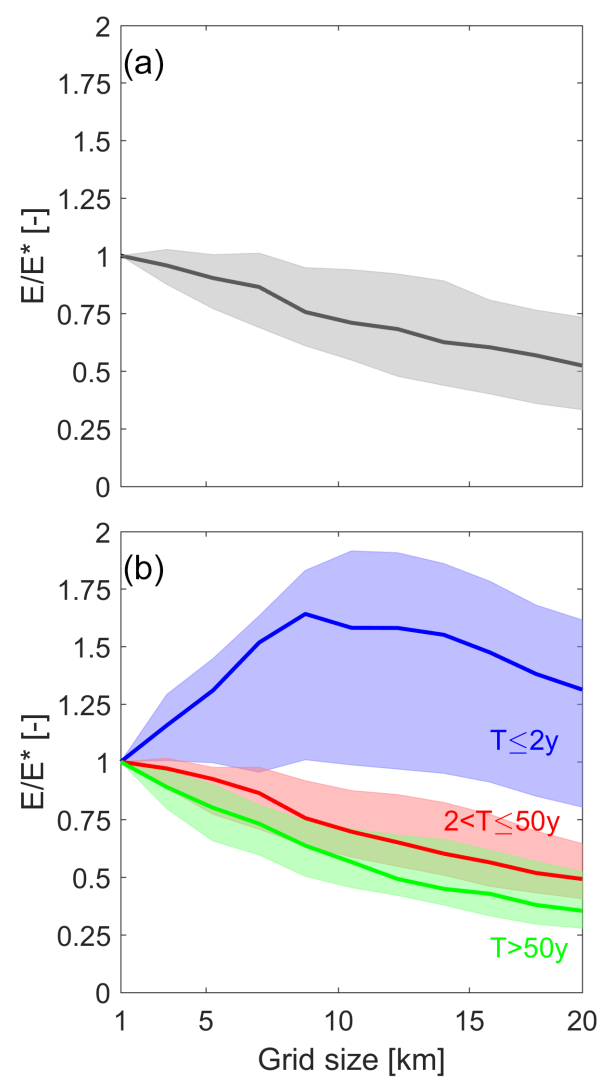

Figure 2. Relative error in the rainfall estimates as a function of the aggregation scale for (a) all the 99 considered debris flow events, and (b) different classes of severity (return period of the $1 \mathrm{~km}$ grid size triggering rainfall). Solid lines show median values and shaded areas the interquartile ranges.

this study, we used $p=5 \%$, but the results we present hold for any probability level lower than $50 \%$, i.e. for any threshold representing a lower envelope curve to the $(E, D)$ pairs. The debris flow occurrence thresholds were calculated, together with the regression relationships (i.e. the thresholds for $p=50 \%$ ) using the rain depth obtained from different aggregation scales, whereas the rainfall duration was kept unchanged. It can be pointed out that, in principle, a biased threshold may be efficient when used with equally biased rainfall estimates. However, Nikolopoulos et al. (2014, 2015a) showed that uncertainty in the estimation of the triggering rainfall strongly decreases the efficiency of thresholds in operational use.

Figure $3 \mathrm{a}-\mathrm{c}$ show the debris flow occurrence thresholds and regression relationships for rainfall aggregated at 1, 10, and $20 \mathrm{~km}$ grid size. As shown by the slope of the relationships in Fig. 3a-c, the shape parameter undergoes only minor variations $(<8 \%)$ with spatial aggregation, implying that, in our sample, the distribution of event severity is approximately uniform with the event duration. Large differences are observed in the scale parameter of the regression relationships $\alpha_{50 \%}$, which decreases from 26.5 at $1 \mathrm{~km}$ grid size to 13.4 at $20 \mathrm{~km}$ grid size. Conversely, minor variations are found for the scale parameter of the $5 \%$ threshold $\alpha_{5} \%$, which rises from 8.2 at $1 \mathrm{~km}$ grid size to 9.4 at $10 \mathrm{~km}$ grid size, and then decreases to 6.5 at $20 \mathrm{~km}$ grid size (Fig. 3ac). Figure $3 \mathrm{~d}-\mathrm{f}$ show the distribution of the $\log$ residuals as a function of the return period of the triggering rainfall for 1 , 10 , and $20 \mathrm{~km}$ grid size. For $1 \mathrm{~km}$ grid size, the $\log$ residuals regularly scale with severity (Fig. 3d). As the information is spatially aggregated, this regular scaling is progressively lost (Fig. 3e-f), due to the different effect of spatial aggregation on moderate/severe and mild events (Fig. 2b).

\section{Comparison between thresholds derived from spatially aggregated and rain-gauge-based estimates}

Synthetic rain gauge networks were produced using the procedure proposed by Nikolopoulos et al. (2015a) and Destro et al. (2017). The location of the rain gauges was randomly generated to obtain densities of $1 / A$, with $A$ set to 10, 20, 50 , and $100 \mathrm{~km}^{2}$. To avoid clustering of the rain gauges, a minimum distance between two synthetic stations was set to $0.5 \sqrt{A}$. Rainfall estimates of the synthetic rain gauges were defined as the value of the radar rainfall corresponding to the simulated gauge locations. The rain gauge estimation of triggering rainfall was then defined as the value reported by the rain gauge closest to the triggering location. This nearestneighbour method proved to be the least-biased estimator for debris-flow-triggering rainfall, when compared with kriging and inverse-squared distance methods (Nikolopoulos et al., 2015a; Destro et al., 2017). The synthetic rain gauge estimation operation was iterated to obtain 100 Monte Carlo realizations for each rain gauge network density. Debris flow occurrence thresholds were derived for each realization and density and the estimated parameters were compared with the ones previously derived from spatially aggregated estimates. The uncertainty related to the synthetic network parameters was quantified as the IQR of the corresponding set of realizations.

Figure 4 shows the relative error of the threshold and regression parameters derived from (a) spatially aggregated and (b) rain-gauge-based estimates, together with the standard deviation of the respective $\log$ residuals (c and d). As anticipated in the previous section, the shape parameter $(\beta)$ slightly increases with the aggregation scale, resulting in an $8 \%$ increase at $20 \mathrm{~km}$ grid size, whereas the regression scale parameter $\left(\alpha_{50} \%\right)$ exhibits a remarkable underestimation, with $-51 \%$ at $20 \mathrm{~km}$ grid size (Fig. 4a). The scale parameter of the threshold $\left(\alpha_{5} \%\right)$ increases up to $\sim 7 \mathrm{~km}$ grid size $(\mathrm{RE}=1.19)$ and then monotonically decreases for larger grid sizes $(\mathrm{RE}=0.79$ for $20 \mathrm{~km}$ grid size, Fig. $4 \mathrm{a})$. This dependence is explained by the combination of two effects: (i) the mean value of the estimated rainfall decreases with spatial aggregation (Fig. 2a) and (ii) the standard deviation of 

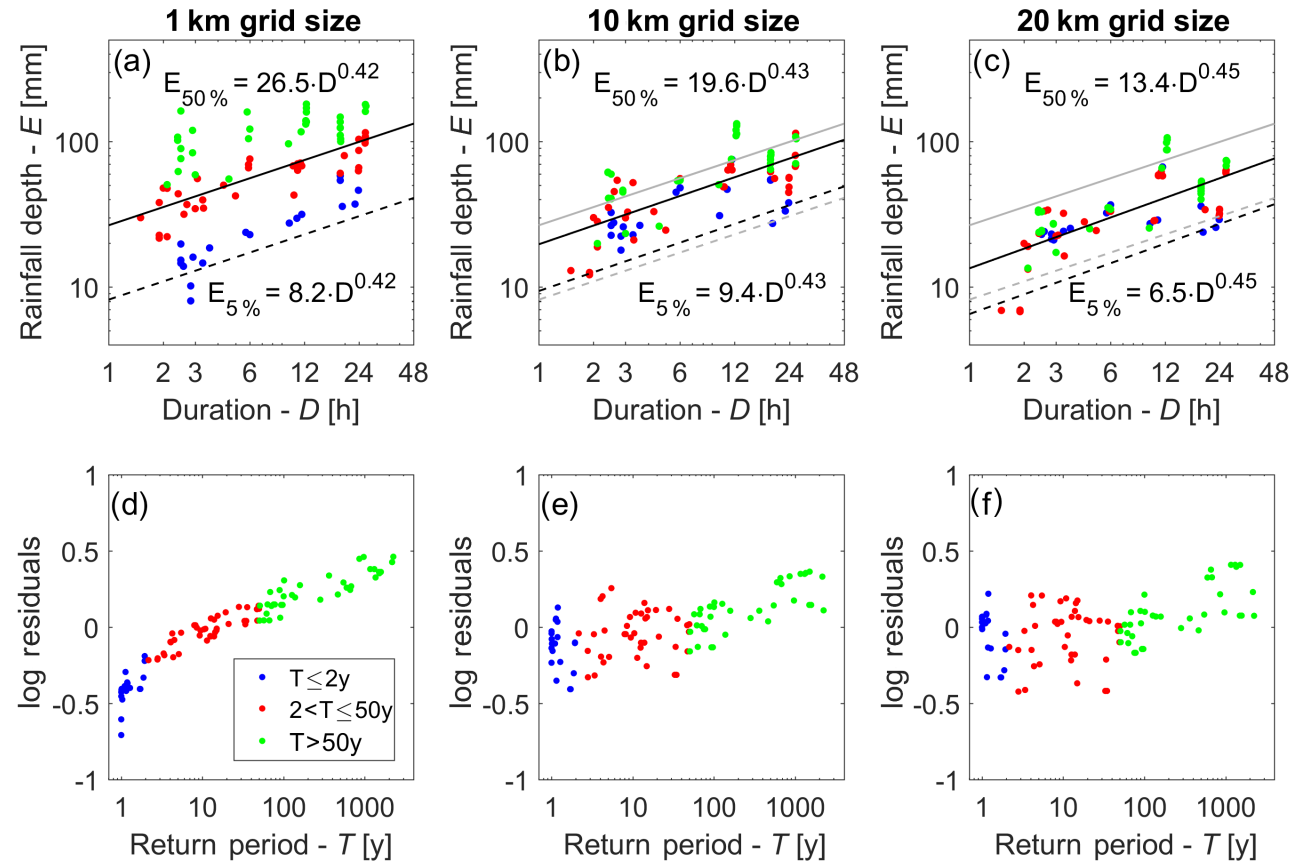

Figure 3. Threshold and regression relationships for 1,10 , and $20 \mathrm{~km}$ grid sizes (a-c, respectively) and corresponding residuals of the regressions in logarithmic scale (log residuals) as a function of the return period of the $1 \mathrm{~km}$ triggering rainfall (d-f). Light grey lines in (b) and (c) reproduce, for reference, the $1 \mathrm{~km}$ grid size relationships.

the log residuals decreases by $\sim 30 \%$ at $10 \mathrm{~km}$ grid size and remains almost unchanged for larger grid sizes (Fig. 4c). This second effect is caused by the dependence of rainfall spatial pattern on the severity seen in Fig. 2b: moderate/severe events are increasingly underestimated and mild events are increasingly overestimated up to $\sim 7 \mathrm{~km}$ grid size, while, for larger grid sizes, the overestimation decreases.

Results obtained using synthetic rain gauge networks are remarkably different (Fig. 4b). The shape parameter $\beta$ exhibits a more marked increase and both $\alpha_{5} \%$ and $\alpha_{50 \%}$ are systematically underestimated. Interestingly, the threshold scale parameter $\alpha_{5} \%$ is more underestimated than the regression scale parameter $\alpha_{50} \%$. This is explained by the large spatial variability of rainfall around the triggering locations: as the network density decreases, the estimation variance of synthetic rain gauge estimates increases, causing the standard deviation of the log residuals to increase (Fig. 4d). As a result, debris flow occurrence thresholds obtained using aggregation scales of $20 \mathrm{~km}$ grid size (corresponding to averaging areas as large as $400 \mathrm{~km}^{2}$ ) are comparable to the ones derived from relatively high-density rain gauge networks, such as $1 / 10 \mathrm{~km}^{-2}$ for $5 \%$ exceedance probability thresholds or $1 / 100 \mathrm{~km}^{-2}$ for $50 \%$ exceedance probability thresholds. Lower densities cause larger errors in both the shape parameter $\beta$ and the scale parameter $\alpha_{5} \%$ of the threshold.

In general, the estimation variance controls the scale parameter of the threshold relationship acting on the standard deviation of the log residuals. In fact, an increased estima-
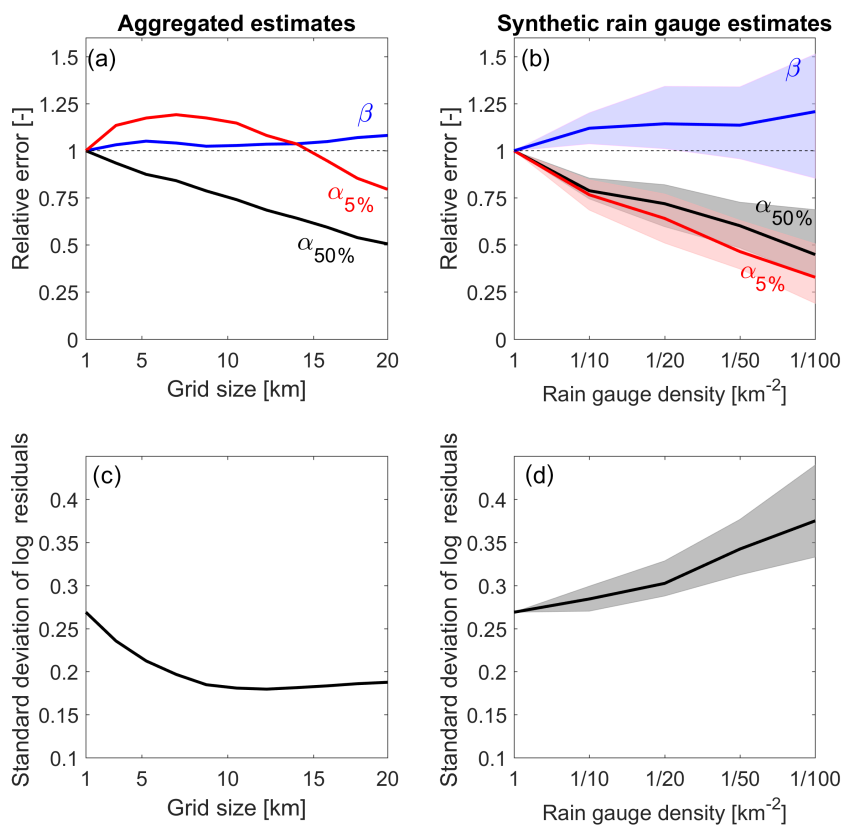

Figure 4. Relative error of the parameters of the debris flow occurrence thresholds and associated regressions (a-b) and standard deviation of the log residuals (c-d) obtained from spatial aggregation of rainfall (a, c), and nearest-neighbour interpolation of synthetic rain gauge networks $(\mathbf{b}, \mathbf{d})$ - shaded areas represent the interquartile range of the Monte Carlo realizations. 
tion variance increases the dispersion of the rainfall depthduration pairs, causing the threshold relationship, a lower envelope curve, to decrease. As reported by Marra et al. (2016), even in the presence of random estimation errors alone, an increase (decrease) in the estimation variance translates into an increase (decrease) in the log residuals, causing the threshold scale parameter to decrease (increase).

\section{Conclusions}

We examined the impact of using spatially aggregated estimates (1-20 km grid size) for the estimation of debris flow triggering rainfall and for the identification of debris flow occurrence thresholds in the form of power law depth-duration relationships.

Results show that errors in the aggregated estimates of debris flow triggering rainfall strongly depend on the severity of the triggering rainfall. Moderate-to-severe triggering rainfall ( $>2$-year return period) is consistently underestimated, whereas mild triggering rainfall ( $\leq 2$-year return period) is generally overestimated up to $20 \mathrm{~km}$ grid size. The estimation variance controls the scale parameter of the threshold relationship, acting on the dispersion of the rainfall depthduration pairs. The impact of spatial aggregation on the derivation of debris flow occurrence thresholds is thus controlled by the different response of mild and moderate/severe triggering rainfall to the spatial aggregation. Consequently, spatial aggregation causes up to 21 and $8 \%$ variation in the scale and shape parameters of the identified debris flow occurrence thresholds. Conversely, rainfall estimates from synthetic rain gauge networks present large estimation variance so that debris flow occurrence thresholds at $5 \%$ exceedance probability derived from densities as high as $1 / 10 \mathrm{~km}^{-2}$ can be comparable to $20 \mathrm{~km}$ grid size spatial aggregation and thresholds from sparser networks are largely underestimated. These findings reveal a complex pattern of scale dependency, which should be considered when identifying and comparing triggering rainfall amounts or debris flow occurrence thresholds derived from different products. In general, rainfall spatial aggregation is more consistent than rain-gaugebased estimation in the identification of the threshold parameters across the examined spatial scales.

Results from this study are subject to uncertainty due to the limited size of the dataset. However, to the authors' knowledge, this is among the largest and most accurate dataset of debris flow triggering rainfall currently available worldwide. It includes $\sim 20 \%$ of the debris flows that have occurred in the study region in the last 15 years and can thus be considered quantitatively representative of the climatology of debris-flow-triggering rainfall in the area. Given the general and objective formulation used, results from this study are qualitatively transferrable to those situations in which lower envelope curves are used to predict the occurrence of pointlike events in the presence of non-stationary fields, such as in the case of shallow landslides (e.g. Guzzetti et al., 2008) or urban flooding (e.g. Yang et al., 2016) prediction.

Future studies, quantifying the impact of (i) estimation uncertainty due to rainfall retrieval algorithms and (ii) temporal resolution of remote-sensing data, are required before the operational use of remotely sensed rainfall products in debris flow early warning systems. To this end, the performance of new satellite-rainfall products (e.g. IMERG, Huffman et al., 2015), available at high space/time resolution (e.g. $0.1^{\circ}$, $0.5 \mathrm{~h}$ ), seems promising and calls for subsequent analysis.

Data availability. Weather radar and debris flow data used for this study are available on the HYLAND project website (http://intra. tesaf.unipd.it/cms/hyland/).

Competing interests. The authors declare that they have no conflict of interest.

Acknowledgements. Francesco Marra was supported by the Lady Davis Fellowship Trust (project: RainFreq). We acknowledge the daily efforts of Ripartizione Opere Idrauliche, Autonomous Province of Bolzano (Italy), for updating the debris flow database and Ufficio Idrografico, Autonomous Province of Bolzano (Italy), Mauro Tollardo in particular, for providing access to the radar data. Comments from the editor, Thom Bogaard, and three anonymous reviewers helped to improve the paper.

Edited by: Thom Bogaard

Reviewed by: three anonymous referees

\section{References}

Abancó, C., Hürlimann, M., Moya, J., and Berenguer, M.: Critical Rainfall Conditions for the Initiation of Torrential Flows, Results from the Rebaixader Catchment (Central Pyrenees), J. Hydrol., 541, 218-229, https://doi.org/10.1016/j.jhydrol.2016.01.019, 2016.

Badoux, A., Andres, N., Techel, F., and Hegg, C.: Natural Hazard Fatalities in Switzerland from 1946 to 2015, Nat. Hazards Earth Syst. Sci., 16, 2747-2768, https://doi.org/10.5194/nhess16-2747-2016, 2016.

Borga M., Stoffel, M., Marchi, L., Marra, F., and Jacob, M.: Hydrogeomorphic response to extreme rainfall in headwater systems: flash floods and debris flows, J. Hydrol., 518, 194-205, https://doi.org/10.1016/j.jhydrol.2014.05.022, 2014.

Brunetti, M. T., Peruccacci, S., Rossi, M., Luciani, S., Valigi, D., and Guzzetti, F.: Rainfall thresholds for the possible occurrence of landslides in Italy, Nat. Hazards Earth Syst. Sci., 10, 447-458, https://doi.org/10.5194/nhess-10-447-2010, 2010.

Caine, N.: The rainfall intensity-duration control of shallow landslides and debris flows, Geogr. Ann. A., 62, 23-27, 1980.

Derin, Y., Anagnostou, E. N., Berne, A., Borga, M., Boudevillain, B., Buytaert, W., Chang, C.-H., Delrieu, G., Hong, Y., Hsu, Y. C., Lavedo-Casimiro, W., Manz, B., Moges, S., Nikolopoulos, E. I., 
Sahlu, D., Salerno, F., Rodriguez-Sanchez, J.-P., Vergara, H. J., and Yilmaz, K. K.: Multiregional Satellite Precipitation Products Evaluation over Complex Terrain, J. Hydrometeorol., 17, 18171836, https://doi.org/10.1175/JHM-D-15-0197.1, 2016.

Destro E., Marra, F., Nikolopoulos, E. I., Zoccatelli, D., Creutin, J. D., and Borga, M.: Spatial estimation of debris flows-triggering rainfall and its dependence on rainfall return period, Geomorphology, 278, 269-279, https://doi.org/10.1016/j.geomorph.2016.11.019, 2017.

Dietrich, A. and Krautblatter, M.: Evidence for Enhanced Debris-Flow Activity in the Northern Calcareous Alps since the 1980s (Plansee, Austria), Geomorphology, 287, 144-159, https://doi.org/10.1016/j.geomorph.2016.01.013, 2017.

Dowling, C. A. and Santi, P. M.: Debris Flows and Their Toll on Human Life: A Global Analysis of Debris-Flow Fatalities from 1950 to 2011, Nat. Hazards, 71, 203-227, https://doi.org/10.1007/s11069-013-0907-4, 2014.

Gariano, S. L. and Guzzetti, F.: Landslides in a Changing Climate, Earth-Sci. Rev., 162, 227-252, https://doi.org/10.1016/j.earscirev.2016.08.011, 2016.

Guzzetti, F., Peruccacci, S., Rossi, M., and Stark, C. P.: The rainfall intensity-duration control of shallow landslides and debris flows: an update, Landslides 5, 3-17, https://doi.org/10.1007/s10346007-0112-1, 2008.

Hong, Y., Alder, R., and Huffman, G.: Evaluation of the Potential of NASA Multi-Satellite Precipitation Analysis in Global Landslide Hazard Assessment, Geophys. Res. Lett., 33, 1-5, https://doi.org/10.1029/2006gl028010, 2006.

Hong, Y., Hsu, K. L., Sorooshian, S., and Gao, X.: Precipitation estimation from remotely sensed imagery using an artificial neural network cloud classification system, J. Appl. Meteor., 43, 18341853, https://doi.org/10.1175/JAM2173.1, 2004.

Hsu, K. L., Gao, X., Sorooshian, S., and Gupta, H. V.: Precipitation estimation from remotely sensed information using artificial neural networks, J. Appl. Meteorol., 36, 1176-1190, https://doi.org/10.1175/15200450(1997)036<1176:PEFRSI>2.0.CO;2, 1997.

Huffman, G. J., Adler, R. F., Bolvin, D. T., Gu, G., Nelkin, E. J., Bowman, K. P., Hong, Y., Stocker, E. F., and Wolff, D. B.: The TRMM multi-satellite precipitation analysis: quasi-global, multi-year, combined-sensor precipitation estimates at fine scale, J. Hydrometeorol., 8, 38-55, 2007, https://doi.org/10.1175/JHM560.1, 2007.

Huffman, G. J., Bolvin, D. T., Braithwaite, D., Hsu, K., Joyce, R., Kidd, C., Nelkin, E. J., and Xie, P.: Algorithm Theoretical Basis Document (ATBD), Version 4.5., NASA Global Precipitation Measurement (GPM) Integrated Multi-satellitE Retrievals for GPM (IMERG), NASA, 2015.

Iverson, R. M.: Debris-flow mechanics, in: Debris Flow Hazards and Related Phenomena, edited by: Jakob, M. and Hungr, O., Springer-Praxis, Heidelberg, 105-134, 2005.

Jakob, M., Owen, T., and Simpson, T.: A Regional RealTime Debris-Flow Warning System for the District of North Vancouver, Canada, Landslides, 9, 165-178, https://doi.org/10.1007/s10346-011-0282-8, 2012.

Joyce, R. J., Janowiak, J. E., Arkin, P. A., and Xie, P.: CMORPH: a method that produces global precipitation estimates from passive microwave and infrared data at high spatial and temporal resolution, J. Hy- drometeorol., $\quad 5, \quad 487-503, \quad$ https://doi.org/10.1175/15257541(2004)005<0487:CAMTPG>2.0.CO;2, 2004.

Kirschbaum, D. B., Adler, R., Hong, Y., Kumar, S., Peters-Lidard, C., and Lerner-Lam, A.: Advances in landslide nowcasting: Evaluation of a global and regional modeling approach, Environ. Earth Sci., 66, 1683-1696, https://doi.org/10.1007/s12665-0110990-3, 2012.

Kirschbaum, D., Adler, R., and Peters-Lidard, C.: Using remotely sensed information for near real-time landslide hazard assessment, edited by: Margottini, C., Canuti, P., and Sassa, K., Landslide Science and Practice, 1, 357-362, https://doi.org/10.1007/978-3-642-31325-7_47, 2013.

Ma, T., Li, C., Lu, Z., and Bao, Q.: Rainfall Intensityduration Thresholds for the Initiation of Landslides in Zhejiang Province, China, Geomorphology, 245, 193-206, https://doi.org/10.1016/j.geomorph.2015.05.016, 2015.

Maggioni, V, Nikolopoulos, E. I., Anagnostou, E. N., and Borga, M.: Modeling Satellite Precipitation Errors Over Mountainous Terrain: The Influence of Gauge Density, Seasonality, and Temporal Resolution, IEEE T. Geosci. Remote, 99, 1-11, https://doi.org/10.1109/TGRS.2017.2688998, 2017.

Marra, F., Nikolopoulos, E. I., Creutin, J. D., and Borga, M.: Radar rainfall estimation for the identification of debrisflow occurrence thresholds, J. Hydrol., 519, 1607-1619, https://doi.org/10.1016/j.jhydrol.2014.09.039, 2014.

Marra, F., Nikolopoulos, E. I., Creutin, J. D., and Borga, M.: Space-time organization of debris flows-triggering rainfall and its effect on the identification of the rainfall threshold relationship, J. Hydrol., 541, 246-255, https://doi.org/10.1016/j.jhydrol.2015.10.010, 2016.

Mei, Y., Anagnostou, E. N., Nikolopoulos, E. I., and Borga, M.: Error Analysis of Satellite Rainfall Products in Mountainous Basins, J. Hydrometeorol., 15, 1778-1793, https://doi.org/10.1175/JHM-D-13-0194.1, 2014.

Nikolopoulos, E. I., Borga, M., Creutin, J. D., and Marra, F.: Estimation of debris flow triggering rainfall: influence of rain gauge density and interpolation methods, Geomorphology, 243, 40-50, https://doi.org/10.1016/j.geomorph.2015.04.028, 2015a.

Nikolopoulos, E. I., Borga, M., Marra, F., Crema, S., and Marchi, L.: Debris flows in the Eastern Italian Alps: seasonality and atmospheric circulation patterns, Nat. Hazards Earth Syst. Sci., 15, 647-656, https://doi.org/10.5194/nhess-15-647-2015, 2015b.

Nikolopoulos, E. I., Crema, S., Marchi, L., Marra, F., Guzzetti, F., and Borga, M.: Impact of uncertainty in rainfall estimation on the identification of rainfall thresholds for debris flow occurrence, Geomorphology, 221, 286-297, https://doi.org/10.1016/j.geomorph.2014.06.015, 2014.

Nikolopoulos E. I., Destro, E., Maggioni, V., Marra, F., and Borga, M.: Satellite-rainfall estimates for debris flow prediction: An evaluation based on rainfall accumulation-duration thresholds, J. Hydrometeorol., 18, 2207-2214, https://doi.org/10.1175/JHMD-17-0052.1, 2017.

Piciullo, L., Gariano, S. L., Melillo, M., Brunetti, M. T., Peruccacci, S., Guzzetti, F., and Calvello, M.: Definition and performance of a threshold-based regional early warning model for rainfall-induced landslides, Landslides, 14, 995-1008, https://doi.org/10.1007/s10346-016-0750-2, 2017.

Rossi, M., Luciani, S., Valigi, D., Kirschbaum, D., Brunetti, M. T., Peruccacci, S., and Guzzetti, F.: Statistical approaches for the 
definition of landslide rainfall thresholds and their uncertainty using rain gauge and satellite data, Geomorphology, 285, 16-27, https://doi.org/10.1016/j.geomorph.2017.02.001, 2017.

Segoni, S., Battistini, A., Rossi, G., Rosi, A., Lagomarsino, D., Catani, F., Moretti S., and Casagli, N.: Technical Note: An Operational Landslide Early Warning System at Regional Scale Based on Space-Time-Variable Rainfall Thresholds, Nat. Hazards Earth Syst. Sci., 15, 853-861, https://doi.org/10.5194/nhess-15-8532015, 2015.
Westra, S., Fowler, H. J., Evans, J. P., Alexander, L. V., Berg, P., Johnson, F., Kendon, E. J., Lenderink, G., and Roberts, N. M.: Future Changes to the Intensity and Frequency of Short-Duration Extreme Rainfall, Rev. Geophys., 52, 522-555, https://doi.org/10.1002/2014rg000464, 2014.

Yang, T. H., Hwang, G. D., Tsai C. C., and Ho., J. Y.: Using Rainfall Thresholds and Ensemble Precipitation Forecasts to Issue and Improve Urban Inundation Alerts, Hydrol. Earth Syst. Sci., 20, 4731-4745, https://doi.org/10.5194/hess-20-4731-2016, 2016. 